\title{
Commentary
}

\section{Canid genomics: Mapping genes for behavior in the silver fox}

\author{
Tyrone C. Spady and Elaine A. Ostrander ${ }^{1}$ \\ Cancer Genetics Branch, National Human Genome Research Institute, National Institutes of Health, \\ Bethesda, Maryland 20892, USA
}

\begin{abstract}
Domestication is the condition and/or process of genetically and environmentally induced developmental adaptation to man and captivity (Price 1984). Several trends are commonly observed in domesticated animals. Most notable are the changes in morphology including pigmentation, size, and relative skeletal proportion (Belyaev 1969; Price 1984). These may be hugely divergent between domestic animals and their progenitor counterparts (Belyaev 1969, 1979; Price 1984; Trut 1999, 2001). Domestication is also associated with marked changes in reproductive physiology, accelerated sexual maturity, increased fecundity, loss of reproductive seasonality, and longer periods of reproductive receptivity. However, it is the behavioral adaptations associated with domestication that are the most dramatic and that have most captured our attention. Domestic animals are said to be "tame", responding to humans in a less-aggressive, often even affable manner. Humans form bonds and often develop lifelong relationships with domestic animals, frequently becoming valued members of the family community. Using the resources presented by Kukekova et al. in this issue of Genome Research, we take a giant step forward in our ability to localize the genes controlling the process of domestication in the canine system (Kukekova et al. 2007).
\end{abstract}

Kukekova et al. (2007) have published the first meiotic linkage map of the silver fox (Vulpes vulpes), which is a color variant of the red fox. It last shared a common ancestor with the domestic dog (Canis familiaris) 10-12 million years ago (Vila et al. 1999a). A colony of silver foxes has been established at the Institute for Cytology and Genetics (ICG) at the Russian Academy of Sciences in Novosibirsk, Russia, with the purpose of developing lines of animals suitable for studying the genetics of domestication. The animals have been selectively bred for nearly half a century for one of the key components to domestication, tame behavior. To date, 34 fox pedigrees have been developed by breeding foxes from tame and aggressive strains (see Fig. 2, below), and then backcrossing $\mathrm{F}_{1}$ progeny to the tame strain. Two additional pedigrees have been produced by crossing tame individuals alone, and one more pedigree by crossing tame to aggressive animals. Crosses and behavioral status of animals used in the crosses are described in more detail below. Genetic analyses of these crosses are likely to provide behaviorists with insights into the genetic underpinnings of complex mammalian behaviors as well as an understanding of the changes associated with the early stages of the domestication process.

Because of the close phylogenetic relationship between the dog and the red fox species complex (Fig. 1A), genomic resources developed previously in the dog have proven useful in the construction of the fox meiotic linkage map. In the late 1990s, both

\section{'Corresponding author.}

E-mail eostrand@mail.nih.gov; fax (301) 480-0472.

Article published online before print. Article and publication date are at http:// www.genome.org/cgi/doi/10.1101/gr.6055807.
Yang and Graphadatsky and their collaborators independently showed that syntenic relationships between the genomes of canid species were largely conserved, despite the marked karyotypic differences (Graphodatsky et al. 1995; Yang et al. 1999). The dog has a karyotype of 78 acrocentric chromosomes, compared with 34 metacentric chromosomes and a variable number of B chromosomes observed in the red fox.

Kukekova et al. (2007) used 320 microsatellite-based markers to construct the fox map. The markers were all either previously published dog microsatellites (Guyon et al. 2003; Breen et al. 2004; Clark et al. 2004), a set of dog markers previously optimized for the fox (Kukekova et al. 2004), or markers made available through the Mammalian Genotyping Service of Marshfield Laboratories (Madison, WI). Markers were also included that were recently developed using data from the 7.6x whole-genome assembly of the domestic dog (Lindblad-Toh et al. 2005). All markers were genotyped using the 37 silver fox pedigrees from the ICG described above. The resulting linkage map covers the entire haploid set of 16 fox autosomes as well as the X chromosome, with an average marker spacing of $\sim 6.8 \mathrm{cM}$, a total map length of $1480 \mathrm{cM}$, and an average Polymorphic Information Content (PIC) in the silver fox of 0.5 (Kukekova et al. 2007). The initial map was composed 43 linkage groups, each of which corresponded to a unique block in the $7.6 \mathrm{x}$ whole-genome assembly of the dog. Alignment of the markers with the dog assembly allowed for consolidation of fox linkage groups into individual chromosomes. Interestingly, the B chromosome segments of the fox are not included in the linkage map presented by Kukekova et al. (2007). B chromosomes were generally believed not to contain genes of major importance, and fluorescence in situ hybridization (FISH) experiments using fox probes against dog chromosome spreads (Yang et al. 1999) support this belief. However, the recent discovery of a highly conserved and seemingly functional C-KIT proto-oncogene copy on a fox B-chromosome suggests that this hypothesis should probably be revisited (Graphodatsky et al. 2005).

The Farm-Fox Experiment, as it has become known, is, in essence, a fast-forwarded reconstruction of man's first exercise in domestication: the domestication of the dog from the gray wolf (Canis lupus). Dogs were the first domesticated species, and studies of canid phylogenetic relationships show that gray wolves are the sole progenitor to the domestic dog (Clutton-Brock 1995; Vila et al. 1997, 1999b; Wayne et al. 1997) (Fig. 1B). The study of genetic diversity across canids indicates that dogs first originated in East Asia and subsequently spread across the prehistoric globe. Archeological evidence places the time of domestication about 14,000-17,000 yr before the present (ybp) (Clutton-Brock 1995; Sablin and Khlopachev 2002). However, molecular evidence suggests it could have occurred much earlier. Mitochondrial data suggests that dogs diverged from wolves, at the earliest, about 135,000 ybp (Vila et al. 1997). However, an analysis of more dogs 
A

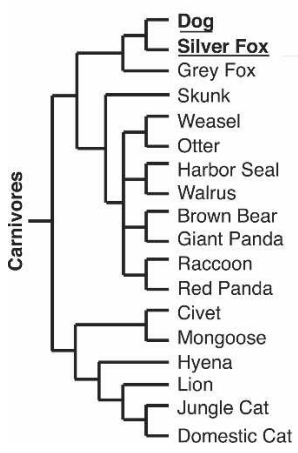

B

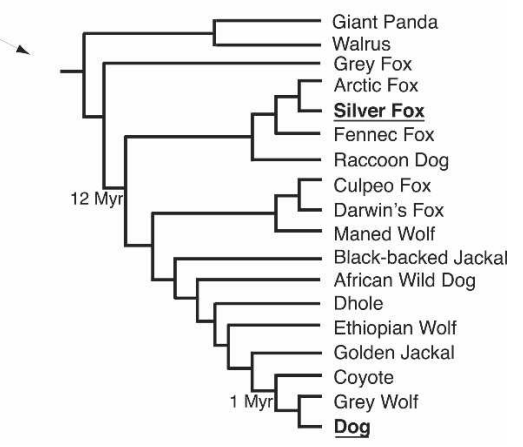

Figure 1. Figure adapted from Vila et al. (1999a). (A) Cladogram depicting the higher-order evolutionary relationships of carnivores, based on DNA hybridation. (B) Cladogram depicting the relationships of a representative subset of extant Canidae, based on mitochondrial sequence data.

and additional mitochondrial sequence data estimates the origin dogs to be between about 11,000 and 40,000 ybp, which is closer to the archeological record (Savolainen et al. 2002). Estimates of such recent divergence events are complicated by the relative high contribution of instantaneous mutation rates to most recently diverged taxa (Ho et al. 2005; Ho and Larson 2006). Therefore, a precise estimate of when dogs became domesticated from wolves is still lacking.

Dmitry Belyaev and colleagues at the ICG in Novosibirsk, Siberia, set out to domesticate the silver fox, a species important in the fur industry that had never been fully domesticated. In their early work, Belyaev and Trut summarized basic behavioral, physiological, and morphological changes that are common to domesticated animals, including a reduction in fear behavior exhibited in response to humans, changes in pigmentation, body size, relative skeletal proportions, and a relaxation of the seasonality of reproductive cycles (Belyaev 1969, 1979; Trut 1999). Belyaev hypothesized that selection based solely on behavior could reconstitute not only the behavioral, but the physiological phenotypic changes associated with domestication (Belyaev 1969, 1979). As described below, his prediction proved to be startlingly true.

In 1959, Belyaev and colleagues started a breeding program consisting of 100 females and 30 male foxes (Trut 1999). Foxes were selected for tameness, with about $20 \%$ of females and $5 \%$ of males being bred. Upon reaching sexual maturity, the behavior of the animals was evaluated. Among the population being selected for tame behavior, four behavioral classes were differentiated. The behavior classes ranged from the least tame, which avoid human contact and would bite if touched by the keepers, to the most tame, which would actively seek human contact and exhibit tail wagging and licking, as is common among domestic dogs (Figs. 2A, 3). By the 10th generation, $18 \%$ of pups bred in a single generation were in the highest tameness class. By the 30 35 th generations, this number soared to $70 \%-80 \%$. The result is a population of tame foxes that behave much as domestic dogs (Trut 1999; Hare et al. 2002, 2005) (Fig. 3).

Despite selecting only for behavior, numerous dog-like morphological and physiological novelties emerged in the foxes (Trut $1999,2001)$. Among some foxes, skulls became wider and snouts became shorter. Individuals with floppy ears, truncated tails, curly tails, and anomalous pigmentation patterns (Figs. 2A, 3), all dog-like traits, were observed in at least some foxes. The farm

foxes also show signs of heritable relaxation of the reproductive cycle, with biannual oestrus appearing in some animals (Trut 2001).

While selecting for tame behavior in one population, researchers at the ICG also developed a population of foxes that preserved the aggressive behavior seen in the wild-type animals (Trut 1999, 2001; Kukekova et al. 2006) (Fig. 2B). An experimental cross between tame and aggressive foxes was generated and the $F_{1}$ was then backcrossed to the parental population of tame foxes (Kukekova et al. 2006). Using the same metrics of tameness as described above and in conjunction with parallel measures for aggressive behavior, a continuum of behavioral phenotypes across all of the farm foxes could be described. The parental tame and aggressive populations were easily resolved at opposite extremes of behavior. Forty-five foxes, the progeny of 10 crosses between the most tame and most aggressive individuals, made up the $\mathrm{F}_{1}$ generation. $F_{1}$ foxes showed behavioral phenotypes roughly intermediate to the parental populations. Finally, a population of 300 backcross foxes, segregating tameness behavior, was generated.

Because studies of genes influencing complex behavior have traditionally been hampered by the difficulty in establishing robust phenotypic assays, Trut and coworkers have opted to measure the physical manifestations of behavior rather than the behavior itself (Trut 2001; Kukekova et al. 2006). During videotaped behavioral tests, scientists were able to objectively quantify a range of traits associated with the tame phenotype; for example, the presence or absence of specific vocalizations, the rela-
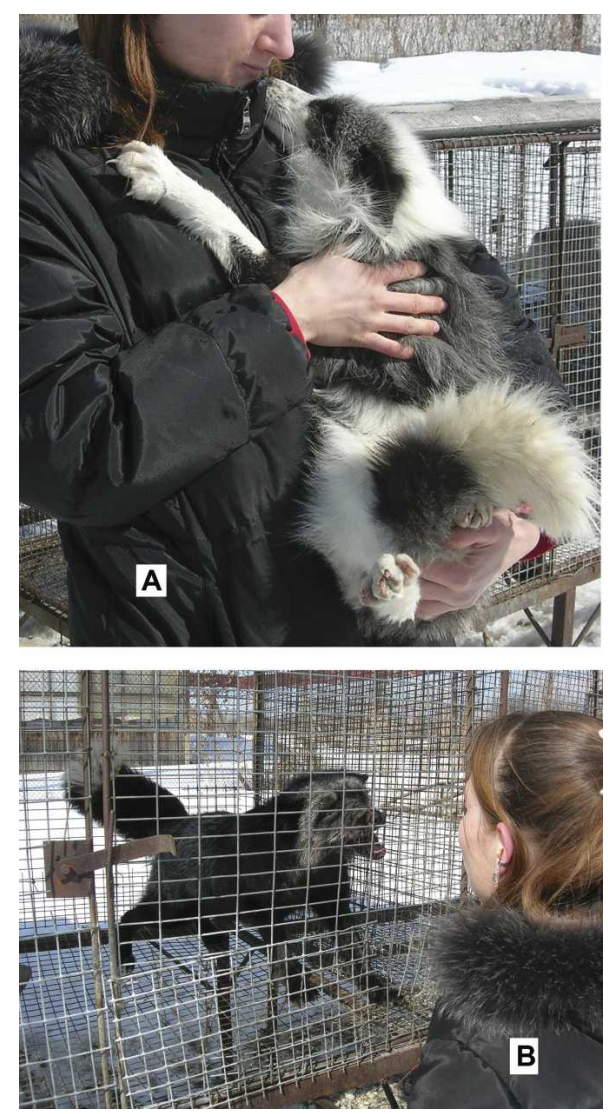

Figure 2. Foxes from the Farm-Fox experiment. (A) Fox from the population being selected for tame behavior. (B) Fox from the population being selected for aggressive behavior. Photographs courtesy of Darya Shepeleva. 


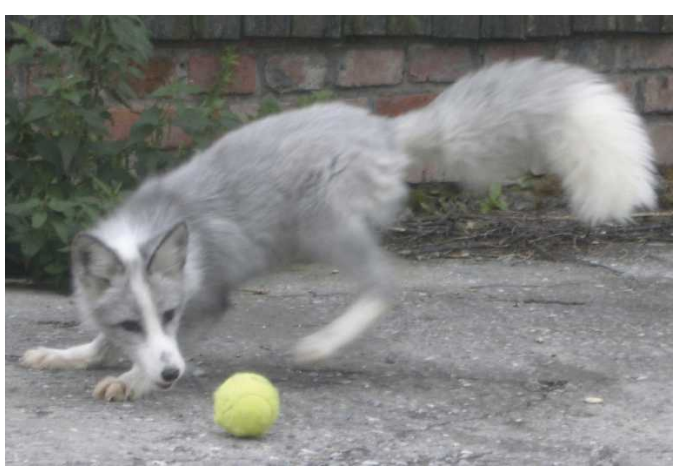

Figure 3. Fox demonstrating some of the dog-like behaviors that characterize the tame population. Play in adulthood is more common among foxes of the tame population. Photograph courtesy of Anna V. Kukekova.

tive positions of key body parts such as the tail, and time spent at certain places in the cage, can all be reproducibly measured and used in principal component analysis (PCA). PCA classifies variation of correlated traits into linear combinations. As such, PCs are phenotypes and subject to genetic analysis. To date, Farm-Fox researchers have defined 50 traits that distinguish the fox populations from one another (Kukekova et al. 2006). Analysis reveals that these traits can be summarized in two PCs, which explain $47.3 \%$ and $6.4 \%$ of the total variation (Kukekova et al. 2006). Thus, Trut and researchers have developed a quantitative and reproducible set of measurements that define major behavioral phenotypes of interest for use in future mapping studies.

Using the experimental cross described above and the new fox linkage map, identification of the genes responsible for tame behavior may now be attempted. The results will be limited, however, by the fact that the map only has 350 markers and will, at best, localize genes of interest to several million base pairs. But fox researchers have an enormous advantage in that extensive resources have been developed for navigating the closely related dog genome. There is a rudimentary canine meiotic linkage map containing a few hundred microsatellite markers (Mellersh et al. 1997; Neff et al. 1999; Breen et al. 2004), but more importantly, there are dense RH maps that allow high-quality comparative mapping to be done. The most developed of those resources contains $>10,000$ genes derived from the $1.5 x$ survey sequence of the Standard Poodle (Kirkness et al. 2003). In the survey sequence, more than 650 million base pairs ( $>25 \%)$ of dog sequence aligned uniquely to the human genome, including fragments of putative orthologs for 18,473 of 24,567 annotated human genes. At least 100 continuous bases from a minimum of one exon were present for nearly $85 \%$ of individual canine genes. In the end, a total of 10,348 gene-based markers were mapped, creating a comparative map of uniformly spaced genes across all canine chromosomes except the Y (Hitte et al. 2005). The map provides a tremendous resource for the fox genomics community.

The final resource of enormous use to the silver fox cloning efforts will be the whole-genome assembly of the $7.6 \mathrm{x}$ canine genome sequence itself. The effort generated over 35 million sequence reads and covers $99 \%$ of the eukaryotic genome (http:// www.genome.ucsc.edu) (Lindblad-Toh et al. 2005). Half of the assembled bases (N50 contig size) are in contigs of $180 \mathrm{~kb}$, and the N50 supercontig size is $45.0 \mathrm{Mb}$. Therefore, as more markers are added to the fox meiotic linkage map, alignment of fox segments against the dog genome will allow even better orientation and order of fox linkage groups to be established.
It is interesting that when the $7.6 \mathrm{x}$ genome sequence and the 10,000 gene dog RH map were compared, there was excellent concordance between the two (Hitte et al. 2005). Indeed, we have argued that most of what is needed for comparative genome mapping can be gathered from 1-2x sequence and a high-quality RH map (Hitte et al. 2005). This can be completed in a fraction of the time and at an incremental cost of what an 8-10x highquality draft sequence would cost. In considering what resources the fox mapping community should next seek, one option is to work toward a survey sequence of $1-2 \mathrm{x}$ as was initially done for the dog (Kirkness et al. 2003), followed by a dense RH mapping effort (Hitte et al. 2005). This resource, combined with what is known from the comparative study of several mammalian $\mathrm{RH}$ maps by Murphy et al. (2005), is likely to provide the fox genetics community with everything they need to move from linkage marker to gene in a timely fashion.

A complementary approach to genetic mapping for the identification of genes underlying fox behavioral phenotypes is to use cDNA microarray technology to assay differential gene expression. Using global human 30,000 cDNA clone microarrays, Lindberg et al. (2005) detected mRNA expression differences between brain regions of farm (tame and nonselected) and wild foxes for $8 \%$ of clones. Many fewer differences $(0.1 \%)$ were observed between tame and nonselected farm foxes. This was probably due, in part, to limitations of the cross-species hybridization between fox cDNA and human cDNA arrays, which are most likely to identify highly conserved genes with large differences in gene expression. Several canine-specific cDNA microarrays have since been developed that will likely provide a more rigorous interrogation of the fox brain transcriptome and produce more useful information about the biological networks involved in fox behavioral differences. The first is a 4000 clone brain-specific array, and the second is a high-density multi-tissue array (Holzwarth et al. 2005; Thomson et al. 2005). However, the cDNA microarray approach has several limitations. First, differentiating between correlated and causative changes will not be possible. Also, a priori knowledge about sampling the most appropriate region(s) of the brain at the right time in development may be lacking. Finally, currently available cDNA platforms are biased toward protein coding genes and do not sample other important genetic elements such as microRNA's. Nevertheless, expression arrays are useful and represent an important strategy for assembling complete information about the genetic regulation of fox behavioral phenotypes.

The fox system is poised to help resolve questions surrounding early domestication as well as expand our understanding of the suite of genes underlying complex behavior. Most promising is that the foxes may help to identify the genes that were important in the early domestication of dogs, when our human ancestors first began to exert selective pressure on wolves. Furthermore, the Farm-Fox system demonstrates that selection for behavior can have far-reaching morphological and physiological effects and also illustrates the possibility that phenotypic diversity could be generated by selection for behavior alone. This could provide important clues to the rates of morphological radiation possible in the dog. Finally, the fox may identify new genes that control complex mammalian behaviors of interest for understanding both naturally occurring as well as anomalous behaviors. Having said that, one has to consider the possibility that population structure has played some role in generating some of the diversity observed in the fox. Farm-Fox researchers were mindful of the potential issues regarding inbreeding and, 
therefore, most of the tame foxes were propagated under a model of outbreeding (inbreeding coefficients between 0.02 and 0.07 ) (Trut 2001). A few tame lines were propagated to be inbred (40\%$60 \%$ homozygosity). The inbred lines do not show higher emergence of phenotypic novelties when compared with the outbred lines. Inbreeding increases the frequency of recessive homozygotes; however, some of the traits in foxes are known not to follow a recessive mode of inheritance. The star phenotype (color pattern mutation), for example, is inherited in an incomplete dominant trait. Thus, inbreeding alone is unlikely to explain what is being observed among the foxes.

\section{Summary}

Ten years ago the fox map could not have been generated with the rapidity and accuracy that it has been today. Genomics is therefore at somewhat of a crossroads as we move away from the study of conventional model organisms and begin to think again like biologists. Asking questions outside of the protected venue of the mouse and rat systems can now be easily done. At least partial genome sequence has or is being generated for a host of mammals with interesting phenotypes including, but not limited to the elephant, opossum, cow, cat, rabbit, hedgehog, armadillo, wallaby, bat, pangolin, tree shrew, platypus, horse, lemur, squirrel, and several others (http://www.genome.gov/10002154). We are no longer restricted to asking questions based on the phenotypes of a select group of model organisms.

It will be tempting to take the genetic results of the FarmFox experiment and generalize it to the 50,000 yr worth of events that shaped the domestication of the dog. But care should be taken. While almost certainly the results of this highly controlled experiment will provide us with stepping stones and a vocabulary for understanding critical genes and pathways that have brought about domestication, the story is apt to be much more complex than can be derived from this one farm experiment. One senses that the fox genetics community itself is wary of over-interpreting their results, and it is our excitement at the bringing together of genomic tools and novel biological and genetic experiments that poses the greatest risk for overinterpretation. Clearly, in becoming genomicists and learning the tricks for easy resource development, we have reawakened ourselves to the world of biology. We need, as always, to temper enthusiasm with caution and apply rigorous standards to the interpretation of data. Having said that, it is entirely appropriate to feel enthusiasm and excitement as we finally begin to understand the genetic forces that have shaped the transition of wild animal to man's best friend.

\section{Acknowledgments}

We thank the many dog owners and field biologists who support our efforts to understand the genetics of natural variation. We also thank Heidi G. Parker and Bridgett M. vonHoldt for helpful comments and/or discussion of this manuscript. T.C.S. and E.A.O. are supported by the Intramural Program of the National Human Genome Research Institute.

\section{References}

Belyaev, D.K. 1969. Domestication of animals. Science 5: 47-52. Belyaev, D.K. 1979. Destabilizing selection as a factor in domestication. J. Hered. 70: 301-308.
Breen, M., Hitte, C., Lorentzen, T.D., Thomas, R., Cadieu, E., Sabacan, L., Scott, A., Evanno, G., Parker, H.G., Kirkness, E., et al. 2004. An integrated 4249 marker FISH/RH map of the canine genome. BMC Genomics 5: 1-11.

Clark, L.A., Tsai, K.L., Steiner, J.M., Williams, D.A., Guerra, T., Ostrander, E.A., Galibert, F., and Murphy, K.E. 2004. Chromosome-specific microsatellite multiplex sets for linkage studies in the domestic dog. Genomics 84: 550-554.

Clutton-Brock, J. 1995. The domestic dog, its evolution, behavior and interactions with people. CUP, Cambridge. UK.

Graphodatsky, A.S., Beklemisheva, V.R., and Dolf, G. 1995. High-resolution GTG-banding patterns of dog and silver fox: Description and comparative analysis. Cytogenet. Cell Genet. 69: 226-231.

Graphodatsky, A.S., Kukekova, A.V., Yudkin, D.V., Trifonov, V.A., Vorobieva, N.V., Beklemisheva, V.R., Perelman, P.L., Graphodatskaya, D.A., Trut, L.N., Yang, F., et al. 2005. The proto-oncogene C-KIT maps to canid B-chromosomes. Chromosome Res. 13: $113-122$.

Guyon, R., Lorentzen, T.D., Hitte, C., Kim, L., Cadieu, E., Parker, H.G., Quignon, P., Lowe, J.K., Renier, C., Gelfenbeyn, B., et al. 2003. A $1-\mathrm{Mb}$ resolution radiation hybrid map of the canine genome. Proc. Natl. Acad. Sci. 100: 5296-5301.

Hare, B., Brown, M., Williamson, C., and Tomasello, M. 2002. The domestication of social cognition in dogs. Science 298: 1634-1636.

Hare, B., Plyusnina, I., Ignacio, N., Schepina, O., Stepika, A., Wrangham, R., and Trut, L. 2005. Social cognitive evolution in captive foxes is a correlated by-product of experimental domestication. Curr. Biol. 15: $226-230$.

Hitte, C., Madeoy, J., Kirkness, E.F., Priat, C., Lorentzen, T.D., Senger, F., Thomas, D., Derrien, T., Ramirez, C., Scott, C., et al. 2005. Facilitating genome navigation: Survey sequencing and dense radiation-hybrid gene mapping. Nat. Rev. Genet. 6: 643-648.

Ho, S.Y. and Larson, G. 2006. Molecular clocks: When times are a-changin'. Trends Genet. 22: 79-83.

Ho, S.Y., Phillips, M.J., Cooper, A., and Drummond, A.J. 2005. Time dependency of molecular rate estimates and systematic overestimation of recent divergence times. Mol. Biol. Evol. 22: $1561-1568$.

Holzwarth, J.A., Middleton, R.P., Roberts, M., Mansourian, R., Raymond, F., and Hannah, S.S. 2005. The development of a high-density canine microarray. J. Hered. 96: 817-820.

Kirkness, E.F., Bafna, V., Halpern, A.L., Levy, S., Remington, K., Rusch, D.B., Delcher, A.L., Pop, M., Wang, W., Fraser, C.M., et al. 2003. The dog genome: Survey sequencing and comparative analysis. Science 301: 1898-1903.

Kukekova, A.V., Trut, L.N., Oskina, I.N., Kharlamova, A.V., Shikhevich, S.G., Kirkness, E.F., Aguirre, G.D., and Acland, G.M. 2004. A marker set for construction of a genetic map of the silver fox (Vulpes vulpes). J. Hered. 95: 185-194.

Kukekova, A.V., Acland, G.M., Oskina, I.N., Kharlamova, A.V., Trut, L.N., Chase, K., Lark, K.G., Erb, H.N., and Aguirre, G.D. 2006. The genetics of domesticated behavior in canids: What can dogs and silver foxes tell us about each other. In The dog and it's genome (eds. E.A. Ostrander et al.), pp. 515-537. Cold Spring Harbor Laboratory Press, Cold Spring Harbor, NY.

Kukekova, A.V., Trut, L.N., Oskina, I.N., Johnson, J.L., Temnykh, S.V., Kharlamova, A.V., Shepeleva, D.V., Gulievich, R.G., Shikhevich, S.G. Graphodatsky, A.S., et al. 2007. A meiotic linkage map of the silver fox. Genome Res. (this issue).

Lindberg, J., Bjornerfeldt, S., Saetre, P., Svartberg, K., Seehuus, B., Bakken, M., Vila, C., and Jazin, E. 2005. Selection for tameness has changed brain gene expression in silver foxes. Curr. Biol. 15: R915-R916.

Lindblad-Toh, K.C.M., Wade, T.S., Mikkelsen, E.K., Karlsson, D.B., Jaffe, M., Kamal, M., Clamp, J.L., Chang, E.J., Kulbokas 3rd, M.C., Zody, E., et al. 2005. Genome sequence, comparative analysis and haplotype structure of the domestic dog. Nature 438: 803-819.

Mellersh, C.S., Langston, A.A., Acland, G.M., Fleming, M.A., Ray, K., Wiegand, N.A., Francisco, L.V., Gibbs, M., Aguirre, G.D., and Ostrander, E.A. 1997. A linkage map of the canine genome. Genomics 46: $326-336$.

Murphy, W.J., Larkin, D.M., Everts-van der Wind, A., Bourque, G., Tesler, G., Auvil, L., Beever, J.E., Chowdhary, B.P., Galibert, F., Gatzke, L., et al. 2005. Dynamics of mammalian chromosome evolution inferred from multispecies comparative maps. Science 309: 613-617.

Neff, M.W., Broman, K.W., Mellersh, C.S., Ray, K., Acland, G.M., Aguirre, G.D., Ziegle, J.S., Ostrander, E.A., and Rine, J. 1999. A second-generation genetic linkage map of the domestic dog, Canis familiaris. Genetics 151: 803-820. 
Price, E.O. 1984. Behavioral aspects of animal domestication. Q. Rev. Biol. 59: 1-32.

Sablin, M.V. and Khlopachev, G.A. 2002. The earliest ice age dogs: Evidence from Eliseevichi 1. Curr. Anthropol. 43: 795-798.

Savolainen, P., Zhang, Y.P., Luo, J., Lundeberg, J., and Leitner, T. 2002. Genetic evidence for an East Asian origin of domestic dogs. Science 298: $1610-1613$.

Thomson, S.A., Kennerly, E., Olby, N., Mickelson, J.R., Hoffmann, D.E., Dickinson, P.J., Gibson, G., and Breen, M. 2005. Microarray analysis of differentially expressed genes of primary tumors in the canine central nervous system. Vet. Pathol. 42: 550-558.

Trut, L.N. 1999. Early canid domestication: The farm-fox experiment. Am. Sci. 87: 160-169.

Trut, L.N. 2001. Experimental studies in early canid domestication. In The genetics of the dog (eds. A. Ruvinsky and J. Sampson), pp. 15-41. CABI Publishing, New York.

Vila, C., Savolainen, P., Maldonado, J.E., Amorim, I.R., Rice, J.E.,
Honeycutt, R.L., Crandall, K.A., Lundeberg, J., and Wayne, R.K. 1997. Multiple and ancient origins of the domestic dog. [see comments] Science 276: 1687-1689.

Vila, C., Amorim, I.R., Leonard, J.A., Posada, D., Castroviejo, J., Petrucci-Fonseca, F., Crandall, K.A., Ellegren, H., and Wayne, R.K. 1999a. Mitochondrial DNA phylogeography and population history of the grey wolf Canis lupus. Mol. Ecol. 8: 2089-2103.

Vila, C., Maldonado, J.E., and Wayne, R.K. 1999b. Phylogenetic relationships, evolution, and genetic diversity of the domestic dog. I. Hered 90: 71-77.

Wayne, R.K., Geffen, E., Girman, D.J., Koeppfli, K.P., Lau, L.M., and Marshall, C.R. 1997. Molecular systematics of the Canidae. Syst. Biol. 46: 622-653.

Yang, F., O’Brien, P.C., Milne, B.S., Graphodatsky, A.S., Solanky, N. Trifonov, V., Rens, W., Sargan, D., and Ferguson-Smith, M.A. 1999. A complete comparative chromosome map for the dog, red fox, and human and its integration with canine genetic maps. Genomics 62: $189-202$. 


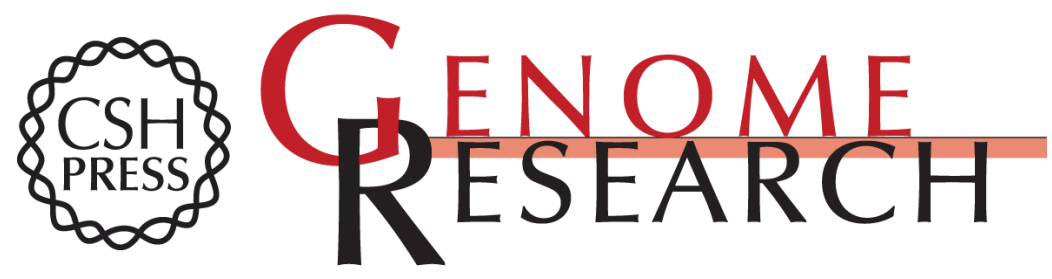

\section{Canid genomics: Mapping genes for behavior in the silver fox}

Tyrone C. Spady and Elaine A. Ostrander

Genome Res. 2007 17: 259-263 originally published online February 6, 2007

Access the most recent version at doi:10.1101/gr.6055807

Related Content

References

\section{http:}

Articles cited in:

http://genome.cshlp.org/content/17/3/259.full.htmI\#related-urls

A meiotic linkage map of the silver fox, aligned and compared to the canine genome

Anna V. Kukekova, Lyudmila N. Trut, Irina N. Oskina, et al.

Genome Res. March, 2007 17: 387-399

\section{License}

Email Alerting

Service
Receive free email alerts when new articles cite this article - sign up in the box at the top right corner of the article or click here.

\section{Affordable, Accurate Sequencing.}

To subscribe to Genome Research go to: https://genome.cshlp.org/subscriptions 